\title{
Community well-being, post-industrial music cities and the turn to popular music heritage
}

Sarah Baker, Raphaël Nowak, Paul Long, Jez Collins, and Zelmarie Cantillon

\section{Introduction}

In this chapter, we interrogate how a turn to popular music heritage can represent an important strategy for reinstating a sense of well-being for disenfranchised communities in post-industrial music cities. Our specific interest is in the potential of popular music heritage initiatives to enhance community members' participation within the socio-cultural (online and offline) spaces of Birmingham, the UK's largest city outside London and one in the process of being branded a 'music city'. With its rich musical heritage, our case study of Birmingham highlights how heritage initiatives can have a positive impact on individuals within a community impacted by industrial decline. The turn to popular music heritage, we argue, can enhance civic pride (Power and Smyth 2016) through the creation of spaces that foster a greater sense of well-being and attachment to place among the community of interest involved in such heritage activity. As this chapter demonstrates, the heritage sector, and in particular the community heritage sector, can make significant contributions to the making of the music city in ways that support the flourishing of local communities.

In recent decades there has been a growing fixation with the preservation of popular music heritage. The extent of this interest has been reflected in the growth of popular music heritage practices in the mainstream and community heritage sectors, and in the increasing attention paid to the preservation, narration and display of popular music's material past by scholars (see Istvandity et al. [eds.] 2019; Baker et al. [eds] 2018; Baker [ed.] 2015; Cohen et al. [eds] 2015). For example, there is now recognition of the pressing need to archive the material remnants of contemporary music cultures around the world. In the community heritage sector, this recognition is reflected in the growing numbers of enthusiast-led physical archives (Baker 2017) and intentional online archives (Collins 2015) devoted to popular music's past which have been established by activist archivists with the intent to safeguard national and local music heritage. The desire to capture stories of popular music's past is also evident in the prodigious number of unintentional archives that form around the sharing of memories online (Collins and Long 2014; 
Long and Collins 2016). In her research on community archives, museums and halls of fame of popular music, Baker (2017) has outlined how participation in such initiatives can be experienced as transformative for volunteers in these institutions. She documents a range of ways the affective and social dimensions of popular music heritage initiatives foster a sense of wellbeing for volunteers (see also Cantillon and Baker 2018). Our question in this chapter concerns how a sense of well-being might flow through to the users of community-led popular music heritage practices in music cities and what potential impacts these initiatives might have on the broader community. We argue that there is great value for music city policies to incorporate the heritage sector in place branding - what Brabazon (2009) calls the GLAM'ing of the imaging of the city, in reference to the role galleries, libraries, archives and museums (GLAM) can play in narratives of economic development and strategies for the transformation of an urban centre to a creative city.

In the first section of this chapter, we introduce Birmingham and its (re)making as a music city. Our attention then turns to a discussion of the concept of 'well-being' in relation to heritage practice. As a way to think through the potential impact of popular music heritage on a community's well-being, we consider diverse examples of music heritage activity taking place in Birmingham. Popular music is an aspect of Birmingham's heritage that has been long overlooked in the city's recent rebranding as a cultural destination, wherein classical forms have been foregrounded amidst a range of high cultural offers. However, the initiatives we outline in this chapter highlight the various ways that heritage can be used to engender civic pride, and, taken together, they offer evidence of the meaningful nature of music to individual and collective identities, as well as providing a basis for theorising popular music heritage's affective dimensions in nurturing well-being and what this means for music city policies.

\section{Cultural Offer in Birmingham: (Re)Making a Post-industrial Music City}

In Birmingham, allied with issues of growth and social inclusion, a concern for well-being among policy makers, planners and social scientists emerged from the economic upheavals of the last half-century and changes to the city's demographics and culture. Situated in the West Midlands, Birmingham was made by the industrial revolution; central to its intellectual (Uglow 
2003) and physical development (Hopkins 1989), its industrial diversity was advertised in its description as 'The City of a Thousand Trades'. In the decades following the Second World War, Birmingham's population expanded as Commonwealth migrants were recruited to aid in rebuilding the city's damaged infrastructure. The arrival of migrants, first from the Republic of Ireland, then the Caribbean and South Asia, shifted the characteristics and shape of community in Birmingham (Wills 2017). With these new migrants living first in low-cost and often poorly maintained inner city housing, this process of settlement also impacted on and transformed the aesthetics, tastes, smells and sounds of the city. These sounds were manifest in terms of the foreign languages and unfamiliar English dialects heard in workplaces, schools, sites of worship and leisure, and on the street, as well as in the music produced and consumed by migrants and, in due course, by those born in the city too.

While the diversification of Birmingham's human capital was a product of urban regeneration and a period of economic prosperity, emergent challenges and perceptions of race as 'problem' (e.g. Rex and Moore 1970) make for a narrative at odds with the city's contemporary celebration of its diversity. The presence of migrants, for instance, was not understood to be permanent, their very cultural appurtenances deemed 'alien' and the contribution of which to local and national identity was often undetermined. Certainly, issues of settlement were paralleled and amplified by wider structural challenges and an economic downturn affecting Birmingham in the 1970s and 1980s. The collapse of the car manufacturing industry and associated supply chain, closure of foundries and the loss of steel pressing plants and light manufacturers resulted in large-scale unemployment, impacting in turn on education, health, transport and welfare: the city's very well-being.

In response to this existential crisis, Birmingham's primary economic and political agents - a Labour-led city council in partnership with business stakeholders - sought to revitalise the city as a post-industrial site amenable to the service sector, aiming to develop and attract business in insurance, banking and conference hosting (Kennedy [ed.] 2004; Brookes et al. 2016). In doing so, this process involved a reimagining of urban identity that sought to challenge the city's negative reputation in order to make it a desirable destination. This transmutation was evident in investment in capital projects such as the building of the National Indoor Arena and Symphony 
Hall. The latter opened in 1991 in order to host the City of Birmingham Symphony Orchestra led by Simon Rattle. In the same year, the D'Oyly Opera Company relocated to the city following in the footsteps of the Sadler's Wells Royal Ballet, now rebranded as the Birmingham Royal Ballet. As one might infer from this high cultural offer (Parker and Long 2004), in terms of music, there was a particular concentration on classical forms rather than a recognition and engagement with the city's rich history of popular music practice.

\section{Cultural policy and popular music heritage in Birmingham}

At one level, the reimagining of Birmingham has met with some success; national and international press coverage of the city's transformation is extensive and its generic nature is regularly lampooned in local social media discourse. Likewise, satirical websites and blogs such as 'Paradise Circus', and its forebear 'Birmingham: It's Not Shit', register often critical responses to physical change and civic boosterism. Reactions suggest that benefits to the communal well-being accruing from assets designed to attract visitors and affluent, cosmopolitan new residents are uncertain. The vision of the city's policy makers and agents of a cultural offer, while expediently capitalising on diversity, is a relatively exclusive one in which citizens and aspects of the local have a relatively passive role (see Parker and Long 2004).

Whether galvanised by the city's revitalisation or in response to its limitations, individuals and communities of interest in Birmingham have demonstrated an aptitude for other types of cultural enterprise. For instance, compared with perceived civic rivals such as Manchester (Peck and Ward [eds] 2004), what is notable about Birmingham's turn to culture is the initial absence or lack of confidence in its history of popular culture as a resource for its rebranding and reimagining. This is an interesting oversight, as the city's long period of urban decline was simultaneously marked by the emergence of a range of popular music artists who achieved national and often significant international success, their energetic affect at odds with Birmingham's status as signifier of the 'embodied experience of modern city life: dull, grey and inhumane' (Parker and Long 2004, 54). Included here are bands such as Black Sabbath, Judas Priest, Electric Light Orchestra and Duran Duran while the work of many other artists attests to the cultural diversity of the city and its productive interrelations: Joan Armatrading, UB40, Steel 
Pulse, Musical Youth and The Beat. Likewise, there are a range of artists who played a part in originating and establishing the bhangra genre (Khabra 2014).

While popular music in all its forms continues to be made anew in Birmingham, a number of authorised and self-authorised music heritage projects (Roberts and Cohen 2014) have been initiated by individuals and cultural organisations to document and celebrate the achievements of the city's diverse musical output. For example, the role of the city's Punjabi community in the development of bhangra was celebrated in 2005 when music development agency Punch Records, supported by the UK's Heritage Lottery Fund (HLF), curated a touring exhibition Soho Road to the Punjab. The HLF likewise supported the Capsule organisation in the curation of Home of Metal, a project founded on an idea and challenge that spoke directly to an absence in the city's cultural offer: 'For too long Birmingham and the Black Country have failed to celebrate what is rightfully theirs, to claim the city and the region as the birthplace of "heavy metal"' (Home of Metal n.d.). In 2011, Home of Metal curated a popular exhibition (held at the Birmingham Museum and Gallery and other regional sites) which explored the roots of heavy metal in the region, revisited in 2019 to celebrate the fiftieth anniversary of the band Black Sabbath and its global influence.

The attention garnered by such projects was a catalyst for a policy review by the Birmingham City Council, its ambit oriented to the urban rebranding project which was apparent in its title: Destination Birmingham: A Music City (2012). The review asked how popular music might aid in underwriting a positive image for the city's 'cultural identity and sense of place', and its potential role in attracting visitors and 'enhancing the quality of life of residents' (BCC 2012, 13). Alongside its economic analysis, the report presented the results of an impact study that highlighted the role that culture plays in the well-being of individuals and communities, generating pride in 'the skills, imagination and creativity in the city' (BCC 2012, 19). In addition to acknowledging the value of contemporary creativity, the report noted the benefits of recognising Birmingham's music heritage. For instance, music heritage might inform a kind of community education, so that 'residents (in particular young people) know what there is to celebrate here and improve internal perceptions and augment civic pride' (BCC 2012, 26). 
Whatever the benign potential of popular music heritage, many recommendations made in the policy review have yet to be implemented. In the absence of official action, a number of selfauthorised, community-led popular music heritage initiatives have emerged, looking beyond the City Council in seeking support from organisations such as Arts Council England (ACE) and the HLF. In doing so, such initiatives take on a variety of forms and connect also with the well-being agenda of contemporary cultural policy in the UK (Oakley, O'Brien and Lee 2013), with project rationales emphasising the capacity for popular music heritage to activate passion, pride and commitment to place and its past. Before considering examples of community-led popular music heritage initiatives in Birmingham, we discuss the concept of well-being and its connections to deindustrialisation and heritage activity.

\section{Well-being Emerging from Heritage Initiatives}

The 2008 global financial crisis had a range of political, economic and cultural ramifications for post-industrial and deindustrialising cities, further highlighting the fragility of traditional manufacturing and port industries in urban centres around the world. When these industries downsize rapidly or close abruptly, entire communities may grapple with poverty, unemployment and urban decay as they struggle to adjust to new economic realities. However, the decline of industry can also necessitate economic diversification. In particular, a turn to arts, culture and heritage - as expressed through, for example, music city initiatives - can offer opportunities to begin redefining community narratives, reframing urban identity and enhancing a sense of well-being.

The concept of well-being is increasingly used in scholarly research in an attempt to understand individuals and communities in relation to their health and happiness. Well-being is also becoming more commonplace in the discourses of community and urban management and planning sectors, where particular initiatives are being interpreted as potentially enhancing community well-being or otherwise altering how individuals feel within their everyday spaces (see Atkinson et al. [eds] 2016). However, in social theory there is a lack of consensus regarding how well-being can be defined, delineated and measured, and debates in this area remain largely theoretical rather than empirically-informed. Nonetheless, there is an emerging body of research 
which explores the potentials for arts, culture and heritage to enhance well-being (see Mchenry 2009; Ander et al. 2013; Bungay and Trish Vella-Burrows 2013; Fenton 2013; Oakley and Lee 2013; Power and Smyth 2016; Wheatley and Bickerton 2017; Cantillon and Baker 2018).

Gilliland and Flinn $(2013,3)$ argue that community-based archival activity offers 'real world' and 'often critical interventions' in 'local, regional and national even international [sic] archival and heritage narratives'. It is a form of grassroots heritage practice that can be 'politically charged with notions of social justice and civil rights', thus having a 'direct impact upon the lives and well-being of communities and their constituents' (Gilliland and Flinn 2013, 16). However, Power and Smyth $(2016,161)$ note that since 2000, although there 'has been an increasing acceptance amongst policymakers and professionals that participating in archival work has real potential to improve community cohesion and individual wellbeing ... the evidence is mostly anecdotal'. In this chapter, we adopt a perspective on well-being that is purposefully open-ended and subjective, encompassing multiple indicators such as civic pride, 'belonging, trust, reciprocity, [and] identity' (Mchenry 2009, 61), all of which can be tied to a sense of place. Our interest here is in engaging with empirical examples from Birmingham in which we draw on the assumption that (certain) social, cultural and urban policies and planning around the making of the music city alter individual and community well-being. In other words, the presence/absence of a sense of well-being in the music city can be observed even though it cannot be measured definitively.

Power and Smyth (2016) suggest that cultural heritage initiatives and practices create spaces that foster a sense of community well-being. Recent research has pointed out how community heritage practices can increase the subjective well-being of those actively involved in them, such as retired volunteers doing preservation work in jazz and country music archives (see Baker 2017; Cantillon and Baker 2018). Indeed, heritage practices can strengthen a sense of community by creating 'mutually supportive atmospheres that can tackle social isolation and enhance people's quality of life and social wellbeing' (Power and Smyth 2016, 162). We argue that the connection between heritage practices, music city-making and well-being is based on three main tenets: first, individuals engage with other members of their community when participating in the preservation of their own local cultures; second, such practices highlight and put to use the 
vernacular knowledge and expertise of community members (see Baker 2017; Cantillon and Baker 2018); and third, the spaces that become defined by popular music heritage practices enhance individuals's attachments to their locality and support the making of the music city. Indeed, a turn to cultural heritage can also provide communities with a narrative about their own history and locality. In the particular case of post-industrial cities, reclaiming 'a new urban narrative' (Kinkead 2016, n.p.) through cultural heritage - and embracing an identity as a music city - can counteract some of the negative stereotypes and the stigma arising from deindustrialisation.

\section{Birmingham's Music Heritage: Digital Archives, Roots and Routes}

In Birmingham, popular music heritage has taken diverse physical and digital forms, with a number of archives, exhibitions and interactive projects (e.g. music maps) emerging in recent years. These projects have been primarily community-based initiatives that invite participation in the recognition and preservation of popular culture. One of the longest-standing examples of popular music heritage is the Birmingham Music Archive (BMA), a digital site founded in 2008 by Jez Collins and originally funded by a research and development grant from ACE. In seeking to 'portray the scope of the city's popular music heritage' (Collins 2015, 82), BMA crowdsources materials by asking users to 'Tell us what you know, tell us what you think!' (Birmingham Music Archive n.d.). At the time of writing, its 7,000 contributors (across the BMA, Facebook and Twitter platforms) had populated the sites with thousands of item entries and comments, uploading digitised artefacts including photographs, posters, flyers, newspapers and magazines, ticket stubs and other music memorabilia.

Appealing to 'anyone who identifies with the city of Birmingham' (Collins 2015, 82), the sharing of individual histories on the site creates what Ketelaar $(2005,54)$ calls a 'community of memory'. In doing so, it can be understood in the context of community archiving and a politics of cultural empowerment, emerging from 'the grassroots activities of documenting, recording and exploring community heritage in which community participation, control and ownership of the project is essential' (Flinn 2007, 153). The significance of the archival record is rooted in 'identity provenance' - that is, collections speak to the identity of the communities that built and 
are served by the archive (Cook 2013,114). Community archives are thus important epistemologically because their parameters are determined by members of the community based on their vernacular knowledge and expertise (Baker and Huber 2013). Any understanding of the well-being generated in such projects echoes the idea that it is bestowed by participation; it is linked to the empowerment of community, with community archives characterised by 'the active and ongoing involvement of members of the source community in documenting and making accessible their history on their own terms' (Stevens et al. 2010, 60, original emphasis).

The resources the BMA generates galvanise 'great memories' (Dave Shuck in Birmingham Music Archive 2014), with the comments of users capturing the affective impacts of participation and how music heritage becomes implicated in collective and personal narratives. As contributor Micki Swann recalls of his experience of 'flower power evenings', citing artists and venues of the past: 'I'm sure our kids think they invented having fun... but those really were the days....Birmingham in 60s. Steve Winwood \& Co...Jim Capaldi when he was with Deep Feeling....Mothers....Moat House...oh great days [sic]' (Birmingham Music Archive 2014). Poster 'Coco' is typical in noting an appreciation for the work of BMA, reflecting on their own contributions that 'nostalgia is whizzing a-way out in to inter-stella space [sic]' (Birmingham Music Archive 2014). However, the archive's aim is not defined by or limited by nostalgic reverie, nor by its digital status. BMA has formed alliances with other enterprises in reaching those citizens to whom the city's popular music heritage is unknown. The BMA's activities extend to events and exhibition curation, educational initiatives and the co-creation of commemorative street art. While these activities involve people for whom popular music heritage is an aspect of their lived memories, they also seek to involve younger generations as a purposeful way to generate feelings of pride in and belonging to place. For example, Figure X.1 depicts a mural located at St Martin's Youth and Community Centre in Highgate, an inner-city suburb of Birmingham. Alongside the roots of the tree are the names of Birmingham reggae bands, including UB40, Steel Pulse, Musical Youth, Jam Jah and Friendly Fire Band - with this musical heritage offering the fertile ground from which contemporary practice can grow. The work was created as part of 'Our Musical Roots', a project designed to investigate and illustrate Birmingham's music heritage and its place in the local community's history and culture. 


\section{<FIGURE X.1 ABOUT HERE>}

Figure X.1: Our Musical Roots Mural, Highgate (Artist: Title; Photograph: Jez Collins).

Supported by HLF funds, the 'Our Musical Roots' project originated with local arts company City of Colours, who worked in conjunction with BMA to run a program designed for under-16s in underprivileged areas in the city. The project design directly addressed aspects of social exclusion that have been identified as a priority for Birmingham (Brookes et al. 2016, 87-8). In doing so, the project sought to address a perceived 'lack' of knowledge about the city's popular musical heritage among younger citizens, seeking to engender a sense of investment in its traditions and possibilities. For Becci Wright, director of City of Colours, the project aimed at 'instilling a sense of pride' in the city's history among its disaffected participants, thus increasing the chances of its preservation (cited in Suzie 2016). At the project's inception, organisers discovered that only 11 per cent of participants were able to name a single musician from Birmingham. The project thus had an educative role; a 10-month training program involved participant attendance at a summer school 'where they took part in a number of music heritage based workshops and activities' (Anon 2016). Participants investigated categories of music culture reflecting the breadth and diversity of the city's communities and its music: dub and reggae; bhangra and Asian produced music; and metal and indie. Participants conducted interviews with musicians, investigated the city's iconic music venues, and in turn shared their knowledge and developing skills with other young people in heritage workshops organised in local schools. Participants produced 're-imagined album covers' that went on to be exhibited at the City of Colours festival (HLF, 2016), as well as two permanent murals (including Figure X.1) and an exhibition.

In this example, faith in the benefits of heritage engagement allied with the well-being objectives of other creative activities. As Bungay and Vella-Burrows $(2013,51)$ argue, performance or the production of art 'has the potential to address young people's sense of self-worth and life skills as a mechanism for promoting behaviour change and healthy lifestyles'. Suggestions that such outcomes were achieved by 'Our Musical Roots' were captured and displayed in the creative expressions of participants, their feelings presented on a series of 'speakers boxes' that were part of the final exhibition event. The words that accompanies the 'speaker box' art works 
highlighted that participants connected with and took ownership of their city's music heritage, understanding its role and value to place: 'Where I come from we play music / It's my heritage my ancestors choose it!'.

Where the City of Colours project sought to illustrate Birmingham's musical roots, other initiatives have highlighted Birmingham's musical routes by way of the production of various accounts of the city's popular music heritage and its formation. In 2010, BMA contributed to this practice as part of plug in, a major exhibition at the Midland Arts Centre. Curated by artist Simon Poulter, plug in reflected Birmingham's changing role as a city, examining its past, present and future and the variety of ways in which culture is expressed and accessed in the city. Affirming the ways in which popular music is a recognisable part of everyday culture, BMA's contribution to plug in came in the form of the co-produced film Made in Birmingham: Reggae Punk Bhangra (2010) and the Birmingham Music Map.

The Birmingham Music Map was a collaborative project with (then) Birmingham-based internet entrepreneur Jon Bounds (n.d.), whose 'projects work in the space where emotion and place collide - online and off'. Bounds created a custom Google Map detailing crowd-sourced contributions from the community at large, invited by a call over social media and local networks. Contributors placed labelled digital pins on the map, each signifying an aspect of musical heritage drawn from individual memories, experiences and local knowledge of the city, so tracking heritage in its spatial as well as temporal dimensions. For the exhibition itself, a physical, etched glass installation of the Birmingham Music Map was created. A more impressionistic rendering of heritage was conveyed by stripping away data relating to place names, streets and landmarks. The reassembled map highlighted clusters of activity, most densely located in the city centre and sparser in the outlying suburbs, prompting viewers to view the city through its musical topography and the layered density of memory. As Bounds noted, 'The printed map acted as an item to explore and jump off rather than a set of closed information' (Long and Collins 2011, 155). As in the other projects described here, the aim was affectively inclusive, designed to aid participation and a sense of shared ownership of the heritage being represented: no hierarchy of person, place, period or genre was imposed. The map evidenced often esoteric vernacular knowledge and a sense of attachment in terms of sites of 
meaning, sometimes highly individualised, often shared. Thus, out in 'the suburbs' one might find pins regarding where a musician was born, or lived while towards the centre of the city, more pins on iconic venues, record stores and sites of subcultural communion.

The ethos of the Birmingham Music Map project is echoed in a further and more recent mapping of Birmingham's music history and heritage illustrated by London-based artist Claire Hartley. Hartley was commissioned as part of for-Wards, a two-year city-wide community arts project aiming to ‘create a cultural sound map of Birmingham' (for-Wards 2017). It involved community contributors in sourcing sounds 'to help to shape the project and raise awareness of the diverse cultures within Birmingham' (for-Wards 2017). Drawing on content curated by BMA, the role of Hartley's map was to plot the city's historical venues, record stores, recording studios and musicians. It connects the past to the present by way of its online iteration in which sites on the map are linked to field recordings being captured by the composers and community collaborations commissioned by for-Wards.

Accessible online as an interactive sound map, the illustration has been printed in poster form, on tote bags and postcards. These are used to promote the project and act also to reinforce the breadth of the city's music heritage whenever these items circulate. Like those other projects described here, for-Wards, in linking music heritage and contemporary creative production, is founded on a concern with the well-being of a community of interest. The desire to create a series of unique compositional pieces that reflect 'a sense of community pride and passion' (forWards 2017), combined with illustrations that circulate throughout the city, speaks to the capacity for music heritage to act as a tool that promotes and enhances local civic engagement while simultaneously supporting the making of Birmingham as a music city.

The projects described above are just a small sample of the actions of a number of organisations that, in the absence of any official or strategic move to formalise Birmingham as a (popular) music city, are actively pursuing an agenda in which confidence in the past signals the potential of present and future creativity. Sharing a commonality of purpose, organisations such as the Birmingham Music Awards, Birmingham Music Coalition, Capsule, Wassifa Sounds, Birmingham Music Archive and others are sharing knowledge and expertise, developing 
partnerships and relationships and pursuing a (sometimes) joined up approach in connecting the musical heritage of Birmingham to its contemporary musical practices. Three brief examples highlight this shift.

Firstly, the Birmingham Music Archive completed in June 2019 a project titled The History Of Grime with the youth centre The Pump (see The Pump 2019). The project is the first attempt to document the contemporary music making of a community of grime creatives through the lens of the genre's historical roots in the city. Working with young people and the grime community, the project has documented the activity of over seventy musicians, managers, entrepreneurs and radio stations, as well as the production of films and documentaries. The project concluded with an exhibition, celebration and impromptu soundclash of young and emerging grime and rap artists. Secondly, in 2018 the Birmingham Music Awards (2018) was 'to bring together and recognise the achievements of musicians and industry professionals across the Midlands'. This initiative is explicit in its mission to celebrate the past, present and future of music, to 'put Birmingham on the map' as a music city. Finally, Simon Delahunty-Forrest, Head of City Design and City Centre Development at Birmingham City Council, has prompted reflections on the conceptualisation and development of infrastructural projects that are changing the urban landscape and their connection with the city's past by introducing developers to cultural organisations and intermediaries. Delahunty-Forrest is interested in how the music, and more broadly cultural, tangible and intangible heritage of Birmingham is understood, respected and incorporated into new developments and how this can be used as place-making for Birmingham, its communities and visitors (Simon Delahunty-Forrest, personal communication with Jez Collins, 20 November 2018 and 6 June 2019).

\section{Conclusion}

This chapter has interrogated the possible connection that exists between popular music heritage initiatives and a sense of well-being for local communities by focusing on the case study of a post-industrial music city - Birmingham, UK. Music city policies, and creative city policies more broadly, 'have been criticised for not delivering tangible benefits for deprived urban communities' (Perry and Symons 2019, 66). The chapter's case study of Birmingham demonstrates how a bottom-up approach to the making of a 'music city' is concerned with the 
connection between the community and culture and what that delivers beyond the rhetoric of local councils in pursuit of economic advantage. By exploring the possible well-being benefits associated with community participation in local popular music heritage initiatives, we suggest that the concept of 'music city' can be enriched by incorporating the actual effects of a turn to music in the rebranding of a city to its local community. As Power and Smyth $(2016,165)$ observe, there are a wide range of benefits associated with community-based heritage conservation, which are tied up with 'firstly, whetting one's appetite and original passion for history and place; secondly, meeting other like-minded people and seeing wider community connections grow; and thirdly, seeing the final "product" come to fruition and sharing it'. By drawing community members together for the sake of collecting, preserving and celebrating a common local culture that makes Birmingham a music city, community heritage projects highlight, and make use of, locals' vernacular knowledges and memories; promote community participation among individuals; and strengthen place-based identities and affective attachments to place. Heritage practices in music cities thus contribute to a local sense of belonging, trust, reciprocity and identity, all identified by Mchenry (2009) as critical for well-being. Enhanced feelings of well-being among a community of interest is a tangible benefit that can be provided in music cities which embrace community-led music heritage initiatives.

The connection between music heritage and community well-being can be tracked in the projects detailed above. While cultural policy-makers have recognised the potential value of heritage projects for branding post-industrial Birmingham as a music city, to date the only concerted implementation of these strategies has been on the part of local community initiatives. As our examples demonstrate, these initiatives have effectively produced ways of engaging citizens with the city's past and contemporary music cultures - both being integral to the production of the cultural and economic value inherent in the music city concept. Projects like those outlined in this chapter are often born of a discontent with how popular music heritage has been overlooked or is in need of preservation. To fill this gap, these projects have approached heritage activity in ways that are participatory and strive for inclusiveness. Such projects call upon and ignite passionate debate and involvement among those for whom such heritage is part of their living memory, as well as sparking interest and engagement among those deemed to be without an understanding of such heritage. 
In the case of Birmingham, which we suggest is indicative of a wider sphere of practice, the engagement with these grassroots initiatives, alongside major projects such as Home of Metal, is an endorsement of the attachment to music, to its value and meaning to community life and identity. They attest to the idea of the music city, not one productive of a homogenous, clearly defined narrative that overlays a meaning of place, but of its ongoing negotiation. Music city policies need to 'recognise that the role of culture in economic regeneration is situated within the context of meaning-making in the everyday' (Perry and Symons 2019, 73). A plurality of possibilities emerges from vernacular knowledge and participation that suggests also a variety of ways of conceiving of, conceptualising and further exploring the realities of well-being in the music city.

\section{REFERENCES}

Ander, Erica, Linda Thomson, Guy Noble, Anne Lanceley, Usha Menon, and Helen Chatterjee. 2013. "Heritage, Health and Well-being: Assessing the Impact of a Heritage Focused Intervention on Health and Well-being." International Journal of Heritage Studies 19 (3): 229-242. https://doi.org/10.1080/13527258.2011.651740.

Anon. 2016. "Birmingham's Musical Heritage Commemorated with Two New Murals for the City." What's On Live. https://www.whatsonlive.co.uk/birmingham/news/birminghamsmusical-heritage-commemorated-with-two-new-murals-for-the-city/36467. Accessed 1 September 2017.

Atkinson, Sarah, Sara Fuller, and Joe Painter, eds. 2016. Wellbeing and Place. London: Routledge.

Baker, Sarah, ed. 2015. Preserving Popular Music Heritage: Do-it-yourself, Do-it-together. London: Routledge.

Baker, Sarah. 2017. Community Custodians of Popular Music's Past: A DIY Approach to Heritage. London: Routledge.

Baker, Sarah, and Alison Huber. 2013. "Notes Towards a Typology of the DIY Institution: Identifying Do-it-yourself Places of Popular Music Heritage.” European Journal of Cultural Studies 16 (5): 513-530. https://doi.org/10.1177/1367549413491721. 
Baker, Sarah, Catherine Strong, Lauren Istvandity, and Zelmarie Cantillon, eds. 2018. The Routledge Companion to Popular Music History and Heritage. London: Routledge. Birmingham City Council. 2012. Destination Birmingham: Birmingham, A Music City. https://www.birmingham.gov.uk/download/downloads/id/450/destination_birmingham_a _music_city_february_2012.pdf. Accessed 19 February 2019.

Birmingham Music Archive. n.d. About Us. http://www.birminghammusicarchive.com/aboutus/. Accessed 19 February 2019. Birmingham Music Archive. 2014. "Midnight City.” Birmingham Music Archive. http://www.birminghammusicarchive.com/midnight-city/. Accessed 28 February 2019. Birmingham Music Awards. 2018. About Us: Awards for Birmingham. https://birminghammusicawards.com/\#!/about. Accessed 30 July 2019.

Brookes, Nadia, Jeremy Kendall, and Lavinia Mitton. 2016. "Birmingham, Priority to Economics, Social Innovation at the Margins." In Social Innovations in the Urban Context, edited by Taco Brandsen, Sandro Cattacin, Adalbert Evers and Annette Zimmer, 83-96. Springer: London.

Bounds, Jon. n.d.. More About Me. http://www.jonbounds.co.uk/about-me/. Accessed 26 July 2017.

Brabazon, Tara. 2009. "Brand Wellington: When City Imaging is GLAM'ed: a Personal View." Branding and Public Diplomacy 5 (4): 260-275. htpps://doi.org/10.1057/pb.2009.22.

Bungay, Hilary, and Trish Vella-Burrows. 2013. "The Effects of Participating in Creative Activities on the Health and Well-being of Children and Young People: A Rapid Review of the Literature." Perspectives in Public Health 133 (1): 44-52. https://doi.org/10.1177/1757913912466946.

Cantillon, Zelmarie, and Sarah Baker. 2018. "DIY Heritage Institutions as Third Places: Caring, Community and Wellbeing Among Volunteers at the Australian Jazz Museum.” Leisure Sciences. https://doi.org/10.1080/01490400.2018.1518173.

Cohen, Sara, Robert Knifton, Marion Leonard, and Les Roberts, eds. 2015. Sites of Popular Music Heritage: Memories, Histories, Places. London: Routledge.

Collins, Jez, and Paul Long. 2015. "Fillin' in any Blanks I Can": Online Archival Practice and Virtual Sites of Musical Memory.” In Sites of Popular Music Heritage: Memories, 
Histories, Places, edited by Sara Cohen, Robert Knifton, Marion Leonard and Les Roberts, 81-96. London: Routledge.

Collins, Jez. 2015. "Doing-it-together: Public History-making and Activist Archiving in Online Popular Music Community Archives.” In Preserving Popular Music Heritage: Do-ityourself, do-it-together, edited by Sarah Baker, 77-90. London: Routledge.

Cook, Terry. 2013. “Evidence, Memory, Identity, and Community: Four Shifting Archival Paradigms." Archival Science 13 (2-3): 19-120.https://doi.org/10.1007/s10502-0129180-7.

Fenton, Hazel. 2013. "Museums, Participatory Arts Activities and Wellbeing." Teaching in Lifelong Learning: A Journal to Inform and Improve Practice 5 (1): 5-12.

Flinn, Andrew. 2007. "Community Histories, Community Archives: Some Opportunities and Challenges." Journal of the Society of Archivists 28 (2): 151-176. https://doi.org/10.1080/00379810701611936.

Flinn, Andrew, Mary Stevens, and Elizabeth Shepherd. 2009. "Whose Memories, Whose Archives? Independent Community Archives, Autonomy and the Mainstream." Archival Science 9 (1): 71-86. https://doi.org/10.1007/s10502-009-9105-2.

for-Wards. 2017. "Updates." http://www.pledgemusic.com/projects/for-wards/updates. Accessed 1 September 2017.

Gilliland, Anne, and Andrew Flinn. 2013. "Community Archives: What are We Really Talking About?" Paper presented at Nexus, Confluence, and Difference: Community Archives meets Community Informatics, Prato CIRN Conference, 28-30 October.

Heritage Lottery Fund. 2016. Our Musical Roots. https://www.hlf.org.uk/our-projects/ourmusical-roots. Accessed 1 September 2017.

Home of Metal. n.d. Background. https://homeofmetal.com/the-project/about/. Accessed 19 February 2019.

Hopkins, Eric. 1989. Birmingham: The First Manufacturing Town in the World, 1760-1840. London: Weidenfeld \& Nicolson.

Istvandity, Lauren, Sarah Baker, and Zelmarie Cantillons, eds. 2019. Remembering Popular Music's Past: Memory-Heritage-History. London: Anthem Press.

Kennedy, Liam, ed. 2004. Remaking Birmingham: The Visual Culture of Urban Regeneration. London: Routledge. 
Ketelaar, Eric. 2005. "Sharing: Collected Memories in Communities of Records." Archives and Manuscripts 33 (20): 44-61.

Khabra, Gurdeep. 2014. Music in the Margins? Popular Music Heritage and British Bhangra Music. International Journal of Heritage Studies 20 (3): 343-355. https://doi.org/10.1080/13527258.2012.758652.

Kinkead, Dan. 2016. "Detroit Case Study.” In Remaking Post-Industrial Cities: Lessons from North American and Europe, edited by Donald K. Carter. New York: Routledge.

Long, Paul, and Jez Collins. 2011. "Mapping the Soundscapes of Popular Music Heritage." In Mapping Cultures: Place, Practice, Performance, edited by Les Roberts, 144-159. New York: Palgrave Macmillan.

Long, Paul, and Jez Collins. 2016. “'My god i loved this tune:)RESPECT 4 POSTING!!!!': Affective memories of music in online heritage practice." In Memory, Space and Sound, edited by Johannes Brusila, Bruce Johnson and John Richardson, 85-101. Bristol: Intellect.

Lordon, Frédéric. 2013. La Société des Affects. Pour un Structuralisme des Passions. Paris: Éditions du Seuil.

Mchenry, Julia Anwar. 2009. "A Place for the Arts in Rural Revitalisation and the Social Wellbeing of Australian Rural Communities." Rural Society 19 (1): 60-70. https://doi.org/10.5172/rsj.351.19.1.60.

Oakley, Kate, Dave O’Brien, and David Lee. 2013. "Happy Now? Well-being and Cultural Policy." Philosophy \& Public Policy Quarterly 31 (2): 18-26.

Parker, David, and Paul Long. 2004. “"The Mistakes of the Past'? Visual Narratives of Urban Decline and Regeneration." Visual Culture in Britain 5 (1): 37-58.

Peck, Jamie, and Kevin Ward, eds. 2002. City of Revolution: Restructuring Manchester. Manchester: Manchester University Press.

Perry, Beth, and Jessica Symons. 2019. "Towards Cultural Ecologies: Why Urban Cultural Policy Must Embrace Multiple Cultural Agendas.” In Cultural Intermediaries Connecting Communities: Revisiting Approaches to Cultural Engagement, edited by Phil Jones, Beth Perry and Paul Long, 63-76. Bristol: Policy Press. 
Power, Andrew, and Karen Smyth. 2016. "Heritage, Health and Place: The Legacies of Local Community-based Conservation on Social Wellbeing." Health \& Place 39: 160-167. https://doi.org/10.1016/j.healthplace.2016.04.005.

The Pump. 2019. The History of Grime. https://www.thepump.org.uk/about-the-hog-project. Accessed 30 July 2019.

Rex, John, and Robert Moore. 1969. Race, Community and Conflict: A Study of Sparkbrook. London: Oxford University Press.

Roberts, Les, and Sara Cohen. 2014. "Unauthorising Popular Music Heritage: Outline Of A Critical Framework." International Journal of Heritage Studies 20 (3): 241-261. https://doi.org/10.1080/13527258.2012.750619.

Stevens, Mary, Andrew Flinn, and Elizabeth Shepherd. 2010. "New frameworks for Community Engagement in the Archive Sector: From Handing Over To Handing On.” International Journal of Heritage Studies 16 (1/2): 59-76. https://doi.org/10.1080/13527250903441770.

Suzie. 2016. "Birmingham's Musical Heritage Commemorated With Pop Up Exhibition." Brumhour. https://brumhour.wordpress.com/2016/11/03/birminghams-musical-heritagecommemorated-with-pop-up-exhibition/. Accessed 1 September 2019.

Uglow, Jenny. 2003. The Lunar Men: Five Friends Whose Curiosity Changed the World. New York: Macmillan.

Wheatley, Daniel, and Craig Bickerton. 2017. Subjective Well-being and Engagement in Arts, Culture and Sport." Journal of Cultural Economics 41 (1): 23-45. https://doi.org/10.1007/s10824-016-9270-0.

Wills, Clair. 2017. Lovers and Strangers: An Immigrant History of Post-war Britain. London: Allen Lane. 